\title{
Structural Properties of Mechanically Activated Rare-Earth Manganites
}

\author{
O.M. Fedorova ${ }^{1}$, A.V. Fetisov ${ }^{1}$, A.Ya. Fishman ${ }^{1, \dagger}$, G.A.Kozhina ${ }^{1, *}$, Kurennykh T.E. ${ }^{2}$, \\ Vedmid L.B. ${ }^{1}$, Vykhodets V.B. ${ }^{2}$ \\ ${ }^{1}$ Institute of Metallurgy, Ural Branch of Russian Academy of Sciences, Ekaterinburg, 620016, Russia
${ }^{2}$ Institute of Metal Physics, Ural Branch of Russian Academy of Sciences, Ekaterinburg, 620990, Russia
*Corresponding Author: gakozhina@yandex.ru
}

Copyright (C) 2014 Horizon Research Publishing All rights reserved.

\begin{abstract}
The effect of mechanical processing in different types of activators on the structure and physicochemical properties of the oxides $\mathrm{LnMnO}_{3+\delta}(\mathrm{Ln}=$ $\mathrm{Sm}, \mathrm{Nd}, \mathrm{La})$ has been studied. The optimal modes of mechanical activation for transformation the oxides under consideration to nanostructured state have been defined. Mechanical processing has been shown to cause a significant change of Jahn-Teller distortion parameters and temperatures of the cooperative Jahn-Teller phase transition. The presence of connection between redox processes and destruction of orbital ordering has been demonstrated. Very low values $\left(10^{-21}-10^{-24} \mathrm{~m}^{2} / \mathrm{s}\right)$ of the oxygen bulk diffusion coefficient have been obtained for the oxides under consideration in the temperature range of $400-750^{\circ} \mathrm{C}$. The diffusion activation energies are close to $1 \mathrm{eV}$, indicating the oxygen diffusion proceeds through structural defects at these temperatures.
\end{abstract}

Keywords Rare-Earth Manganites, Mechanical Activation, X-ray Diffraction, Jahn-Teller transition, Oxygen Diffusion

\section{Introduction}

Rare Earth Manganites possess multiferroic effects, the colossal magnetoresistance and other unique properties $[1,2]$. These compounds are perspective materials in terms of their use as catalysts in redox reactions [3], gas sensors [4], converters, bolometers [5], as well as materials for optoelectronics [6], spintronics [7, 8], magnetic storage media and magnetic sensors [9], resistive and magnetoresistive materials. Interest in the properties of manganites is caused by strongly pronounced correlation between their crystal structure, magnetic, dielectric and transport properties. Among rare earths manganites, $\mathrm{LaMnO}_{3}$ with various substitutions is the most widely and deeply investigated [1, 2]. Physical properties of the compounds of stoichiometric cation composition were found to be adjusted by changing the oxygen nonstoichiometry [10]. Self-doped compounds $\mathrm{La}_{0,88} \mathrm{MnO}_{\mathrm{x}}$ undergo a sequence of transitions: orbitally ordered antiferromagnetic $(x=2.82)$ ferromagnetic insulator $(x=2.9)$ - ferromagnetic metal $(x>2.91)$ with increasing oxygen content and increasing manganese valence [11]. Due to heterovalent substitution of cations in doped manganites $\mathrm{Ln}_{1-\mathrm{x}} \mathrm{A}_{\mathrm{x}} \mathrm{MnO}_{3 \pm \delta}(\mathrm{Ln}=$ rare earth element, $\mathrm{A}=$ divalent metal cation, $\delta=$ oxygen non-stoichiometry), there is a variable oxidation degree of manganese, which is responsible for the appearance of the colossal magnetoresistance and other unique properties of these materials [12]. The substitution of $\mathrm{La}$ in the $\mathrm{LaMnO}_{3}$ manganite for another rare earth element (in particular, $\mathrm{Ce}$, $\mathrm{Pr}, \mathrm{Nd}, \mathrm{Sm}, \mathrm{Gd}$ ) was shown to greatly affect the structure, thermodynamic stability, transport, electrical and magnetic properties [13-15]. The results of recent studies [16, 17] suggest the possibility of obtaining new data in this area.

In light of the various functional applications, oxide materials with nanocrystalline structure are of particular interest (due to specific physico-chemical properties). Mechanical activation method for preparation of nanopowder materials became popular mainly for metal systems. This method has been applied to manganites of rare earth elements in this work.

Mechanical activation is one of the most effective tools to modify the structure and properties of materials. Mechanical grinding not only allows to reduce the particle size to nano-scale, but also may lead to formation of structural defects, metastable crystalline and amorphous phases, to an increase in reactivity and catalytic activity of materials, appearance of the quantum tunnelling effect, change in the electron structure of materials and, as a consequence, the appearance of unusual optical, electrical and magnetic properties [18-20]. To manipulate the functional properties of $\mathrm{LnMnO}_{3}$ manganites by mechanical activation purposefully and efficiently one should determine the influence of different methods of grinding, the types of equipment used, etc. on their structure and physicochemical properties.

This work deals with the effect of mechanical treatment in 
different types of activators on the structure and some physicochemical properties of the material being ground. The manganites $\mathrm{SmMnO}_{3}, \mathrm{NdMnO}_{3}$ and $\mathrm{LaMnO}_{3}$ with a perovskite structure are chosen as the object of study.

\section{Experiment}

Manganites $\mathrm{LnMnO}_{3}(\mathrm{Ln}=\mathrm{Sm}, \mathrm{Nd}, \quad \mathrm{La})$ were synthesized from oxides $\mathrm{Ln}_{2} \mathrm{O}_{3}$ and $\mathrm{Mn}_{2} \mathrm{O}_{3}$ ("especially pure" grade) by ceramic technology with annealing in air at $1400^{\circ} \mathrm{C}$ for 90 hours followed by cooling in the furnace.

Mechanical activation of the synthesized oxides was carried out using three types of activators: 1) planetary ball mill AGO-2 with water cooled drums at its most intense mode with a centrifugal factor of $60 \mathrm{~g}$ (set material $-\mathrm{Fe}$ ), 2) FRITSCH planetary mill PULVERISETTE 06-102 with drums of yttrium-stabilized zirconium oxide with acceleration of $9 \mathrm{~g}$ and 3) FRITSCH planetary mill PULVERISETTE 7 premium line with acceleration of $80 \mathrm{~g}$. In the first case, the treatment of the powders was performed after the preliminary mill lining. The milling duration range was: 30 seconds - 10 minutes in the first case, $1-10$ hours in the second case and $2-10$ minutes in the third case. The phase composition of the obtained materials, the size of coherent scattering regions (CSR) and microstrain were determined radiographically.

$\mathrm{X}$-ray diffraction (XRD) analysis of the samples was performed on SHIMADZU diffractometer XRD-7000 using $\mathrm{CuK} \alpha$-radiation with a monochromator. Shooting was realized in regime of stepwise scanning in the angle range of $20-70^{\circ}$ with a step $\Delta(2 \theta)=0.02^{\circ}$ and 3 second exposure at each point. Silicon was used as an external standard.

High temperature $\mathrm{X}$-ray studies were carried out on a sample heating attachment HA-1001 (Shimadzu) in the following mode: heating in the temperature range $500-1400^{\circ} \mathrm{C}$ at the rate of $10^{\circ} \mathrm{C} / \mathrm{min}$., holding for 10 minutes after every $100^{\circ} \mathrm{C}$, surveying in the angle range of $20-60^{\circ}$ on $2 \Theta$ scale with a step of $0.02^{\circ}$ and 3 seconds exposure.

Thermal analysis was performed on a synchronous thermal analyzer STA 449 F3 (NETZSCH) in a stream of air. The temperature program included heating the samples from ambient temperature to $1200^{\circ} \mathrm{C}$ at the rate of $10^{\circ} \mathrm{C} / \mathrm{min}$ and cooling to $400^{\circ} \mathrm{C}$ at the same rate.

The surface of oxides was studied by X-ray photoelectron spectroscopy (XPS) using Omicron Multiprob spectrometer. The energy scale of the spectrometer was calibrated by the binding energies of the peaks: $\mathrm{Au} 4 f_{7 / 2}(84.00 \mathrm{eV}), \mathrm{Ag} 3 d_{5 / 2}$ $(368.29 \mathrm{eV})$ and $\mathrm{Cu} 2 p_{3 / 2}(932.67 \mathrm{eV})$. The value of samples surface charge was determined by the difference between the measured binding energy of the $\mathrm{C} 1 s$ signal due to $\mathrm{C}-\mathrm{H}$ groups and the value of $285.0 \mathrm{eV}$. High-resolution spectrum was recorded at $E P E=20 \mathrm{eV}$ with $0.05 \mathrm{eV}$ energy step, exposure time of $7.5 \mathrm{~s}$ ( 15 scans by $0.5 \mathrm{~s}$ ). The accuracy of peak position determination in the latter case was $0.1 \mathrm{eV}$. Decomposition of the spectra into components and extraction of the background were performed by the Shirley method using the program XPSPeak 4.1.

Oxygen isotope exchange (OIE) study was carried out by nuclear microanalysis [21].

\section{Results and Discussion}

\subsection{Structure of Mechanoactivated Manganites}

The synthesized samples of $\mathrm{SmMnO}_{3+\delta}$ and $\mathrm{NdMnO}_{3+\delta}$ had perovskite-type orthorhombic structure $(\mathrm{Pbnm})$ with unit cell parameters at room temperature: $a=0.5375(3)$, $b=0.5834(4), c=0.7505(4) \mathrm{nm}$ for $\mathrm{SmMnO}_{3+\delta}$ and $a=0.540$ $8(4), b=0.5817(1), c=0.7548(4) \mathrm{nm}$ for $\mathrm{NdMnO}_{3+\delta}$. The structural analysis data on $\mathrm{LaMnO}_{3}$ were published in [22].

Mechanoactivation of $\mathrm{SmMnO}_{3+\delta}$ in AGO-2 mill resulted in a nanostructured powder after 30 seconds treatment. The lattice parameters and the size of coherent scattering regions (D) are shown in Table 1.

Analysis of the angular dependence of the integral width of XRD peaks suggests that the line broadening is due not only to decrease in coherent scattering regions but also the emergence of the type-II stresses and the corresponding microstrains. Application of the Williamson-Hall method has shown that microstrains are anisotropic. Table 1 presents the average microstrain values $(\varepsilon)$, so they should be considered as estimates.

One can see from Table 1 and Fig. 1 that with increasing duration of mechanical activation from 30 to 90 seconds a slight decrease in the size of coherent scattering regions and a significant increase in microstrain occur. Conventionally optimal milling duration obtained by intersection of curves $D$ and $\varepsilon\left(t_{o p t}\right.$ in Fig. 1$)$ is $15-20$ seconds for the mill AGO-2.

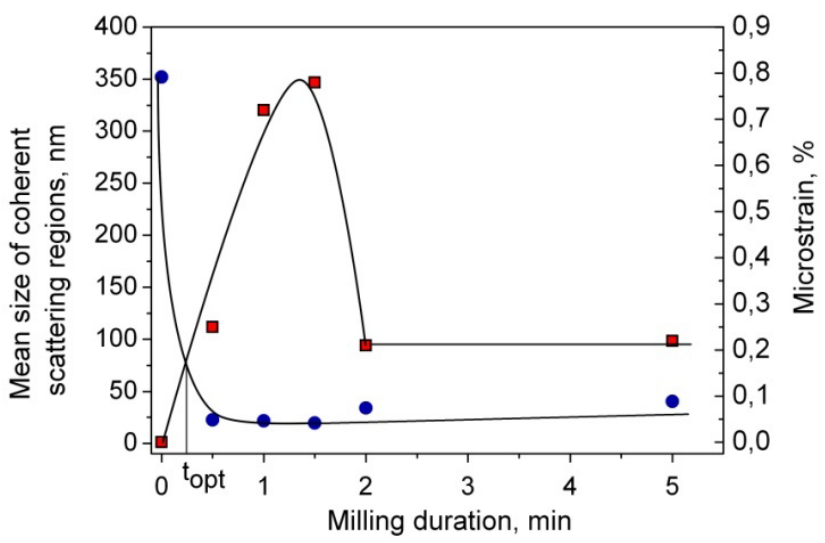

Figure 1. Change of the size of $\mathrm{X}$-ray coherent scattering regions and microstrain for $\mathrm{SmMnO}_{3}$ mechanically activated in an AGO-2 mill.

Nonmonotonic changes of the microstrain amount and the size of coherent scattering regions with increase in the milling duration are associated with merging of nanoparticles into larger particles, recrystallization in some extent, motion of defects and stress relaxation after certain duration of mechanical processing in a high energy mill. 
XPS results have shown that iron oxides in amount of $0.3-3 \%$ appear in samples after mechanical activation in a planetary mill AGO-2; that influences on magnetic properties of the materials under treatment. Possible contamination of the milled powder by the mill set material $(\mathrm{Fe})$ is a feature of this method of mechanical activation.

Table 2 presents the data for samarium manganite samples treated in a mill PULVERISETTE 06-102 with drums of zirconium oxide.

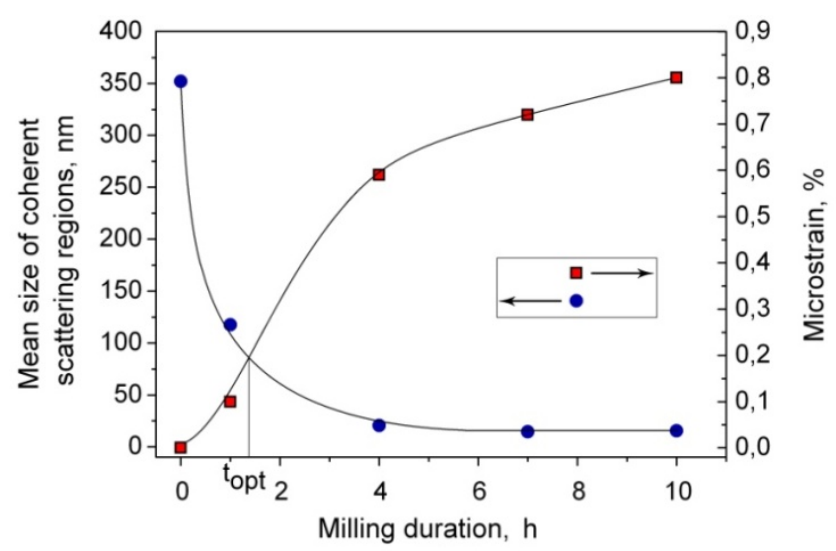

Figure 2. Change of the size of x-ray coherent scattering regions and microstrains for $\mathrm{SmMnO}_{3}$ mechanically activated in PULVERISETTE 06-102.

Figure 2 demonstrates that under processing in the mill PULVERISETTE 06-102 the crystallite size decreases monotonically with grinding time. The greatest change of the powder fineness occurs for the first 2 hours of treatment. Microstrains grow concurrently with the particle size reduction. The crystal lattice parameters also change: parameter $a$ decreases and $c$ increases. The unit cell volume decreases monotonically with increasing mechanoactivation duration to 7 hours. Certain change of trend has been recorded on samples ground for 10 hours: an increase in the unit cell volume $V$ and a slight increase in the size of coherent scattering domains. Microstrains, however, continue its growth.

According to XRD data an increase in milling duration leads to contamination of the samples by the mill and balls material $\left(\mathrm{ZrO}_{2}\right)$. The first traces of zirconium dioxide appear after 4 hours grinding, the impurity amount is about $6 \%$ after mechanical activation for 10 hours.

One more mill was tested to produce nanostructured samarium manganite - a FRITSCH PULVERISETTE 7 premium line mill with glasses and grinding bodies of tungsten carbide. It took 10 minutes to obtain nanopowder of $\mathrm{SmMnO}_{3}$. Structural characteristics of the resulting materials are presented in Table 3.

A decrease in the size of coherent scattering regions and an increase in microstrain with increasing treatment duration occur gradually. The crystal lattice parameters change monotonically: parameters $a, b$ and $V$ decrease. The most significant change of the powder fineness is observed within first 2 minutes of mechanical activation (see Fig. 3).

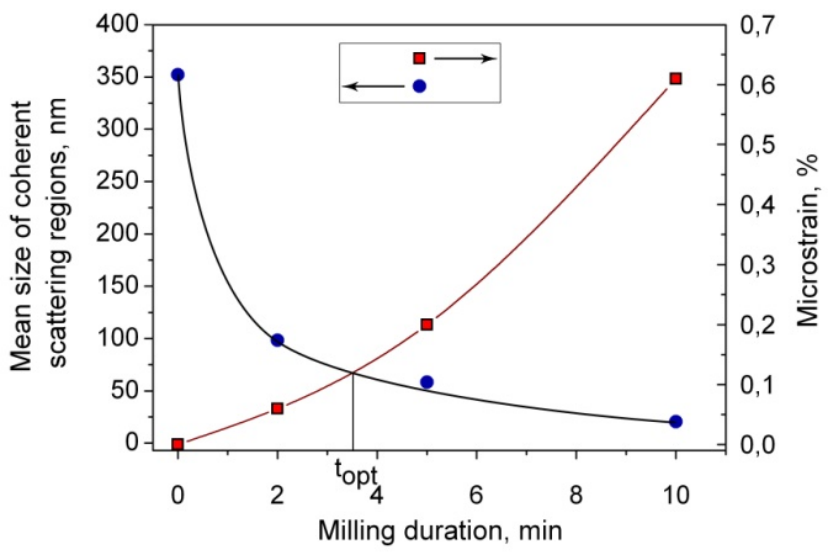

Figure 3. Change of the size of $x$-ray coherent scattering regions and microstrains for $\mathrm{SmMnO}_{3}$ milled in PULVERISETTE 7 premium line.

X-ray diffraction analysis of $\mathrm{SmMnO}_{3+\delta}$ samples has not revealed the presence of the impurities related to the material of the mill PULVERISETTE 7 set. The relative purity of the powder activated in this mill is the advantage of such technology of obtaining nanostructured materials.

Table 1. Structural characteristics of $\mathrm{SmMnO}_{3}$ samples milled in AGO-2

\begin{tabular}{|c|c|c|c|c|c|c|}
\hline \multirow{2}{*}{$\begin{array}{l}\text { Milling duration } \\
\text { (s) }\end{array}$} & \multicolumn{3}{|c|}{ Crystal lattice parameters } & \multirow{2}{*}{$\begin{array}{l}\text { Unit-cell volume } \\
\qquad V\left(\mathrm{~nm}^{3}\right)\end{array}$} & \multirow{2}{*}{$D(\mathrm{~nm})$} & \multirow{2}{*}{$\varepsilon(\%)$} \\
\hline & $a(\mathrm{~nm})$ & $b(\mathrm{~nm})$ & $c / \sqrt{ } 2(\mathrm{~nm})$ & & & \\
\hline 0 & $0.5375(3)$ & $0.5834(4)$ & $0.5307(4)$ & 0.23532 & 352.1 & 0 \\
\hline 30 & $0.5375(3)$ & $0.5833(4)$ & $0.5307(5)$ & 0.23533 & 22.5 & 0.25 \\
\hline 60 & $0.5384(3)$ & $0.5816(4)$ & $0.5305(5)$ & 0.23495 & 21.5 & 0.72 \\
\hline 90 & $0.5374(3)$ & $0.5828(4)$ & $0.5312(5)$ & 0.23531 & 19.5 & 0.78 \\
\hline 120 & $0.5373(3)$ & $0.5832(4)$ & $0.5313(5)$ & 0.23543 & 33.9 & 0.21 \\
\hline 300 & $0.5367(3)$ & $0.5826(4)$ & $0.5304(5)$ & 0.23457 & 40.4 & 0.22 \\
\hline
\end{tabular}


Table 2. Structural characteristics of $\mathrm{SmMnO}_{3}$ samples milled in PULVERISETTE 06-102

\begin{tabular}{|c|c|c|c|c|c|c|}
\hline \multirow{2}{*}{$\begin{array}{c}\text { Milling duration } \\
(\mathrm{h})\end{array}$} & \multicolumn{3}{|c|}{ Crystal lattice parameters } & \multirow{2}{*}{$\begin{array}{c}\text { Unit-cell volume } \\
V\left(\mathrm{~nm}^{3}\right)\end{array}$} & $D(\mathrm{~nm})$ & $\varepsilon(\%)$ \\
\cline { 2 - 6 } & $a(\mathrm{~nm})$ & $b(\mathrm{~nm})$ & $c / \sqrt{ } 2(\mathrm{~nm})$ & 0.2361 & 352.1 & 0 \\
\hline 0 & $0.5376(3)$ & $0.5854(4)$ & $0.5305(4)$ & 0.2360 & 117.5 & 0.10 \\
\hline 1 & $0.5379(3)$ & $0.5853(4)$ & $0.5302(5)$ & 0.2358 & 20.4 & 0.59 \\
\hline 4 & $0.5354(3)$ & $0.5835(4)$ & $0.5339(5)$ & 0.2350 & 14.5 & 0.72 \\
\hline 7 & $0.5336(3)$ & $0.5839(4)$ & $0.5334(5)$ & 0.2374 & 15.4 & 0.80 \\
\hline 10 & $0.5297(3)$ & $0.5881(4)$ & $0.5390(5)$ & & & 0 \\
\hline
\end{tabular}

Table 3. Structural characteristics of $\mathrm{SmMnO}_{3}$ samples milled in PULVERISETTE 7 premium line.

\begin{tabular}{|c|c|c|c|c|c|c|}
\hline \multirow{2}{*}{$\begin{array}{l}\text { Milling duration } \\
\text { (min) }\end{array}$} & \multicolumn{3}{|c|}{ Crystal lattice parameters } & \multirow{2}{*}{$\begin{array}{l}\text { Unit-cell volume } \\
\qquad V\left(\mathrm{~nm}^{3}\right)\end{array}$} & \multirow{2}{*}{$D(\mathrm{~nm})$} & \multirow{2}{*}{$\varepsilon(\%)$} \\
\hline & $a(\mathrm{~nm})$ & $b(\mathrm{~nm})$ & $c / \sqrt{ } 2(\mathrm{~nm})$ & & & \\
\hline 0 & $0.5376(3)$ & $0.5854(4)$ & $0.5305(4)$ & 0.2361 & 352.1 & 0 \\
\hline 2 & $0.5368(3)$ & $0.5839(3)$ & $0.5300(4)$ & 0.2349 & 98.4 & 0.06 \\
\hline 5 & $0.5370(3)$ & $0.5838(4)$ & $0.5300(5)$ & 0.2349 & 58.5 & 0.20 \\
\hline 10 & $0.5367(3)$ & $0.5805(4)$ & $0.5320(5)$ & 0.2344 & 20.5 & 0.61 \\
\hline
\end{tabular}

Similar results were obtained for $\mathrm{NdMnO}_{3}$. Figure 4 shows the changes in the average size of the coherent scattering regions versus duration of mechanical activation in high-energy mills AGO-2 (AGO) and PULVERISETTE 7 premium line (P7).

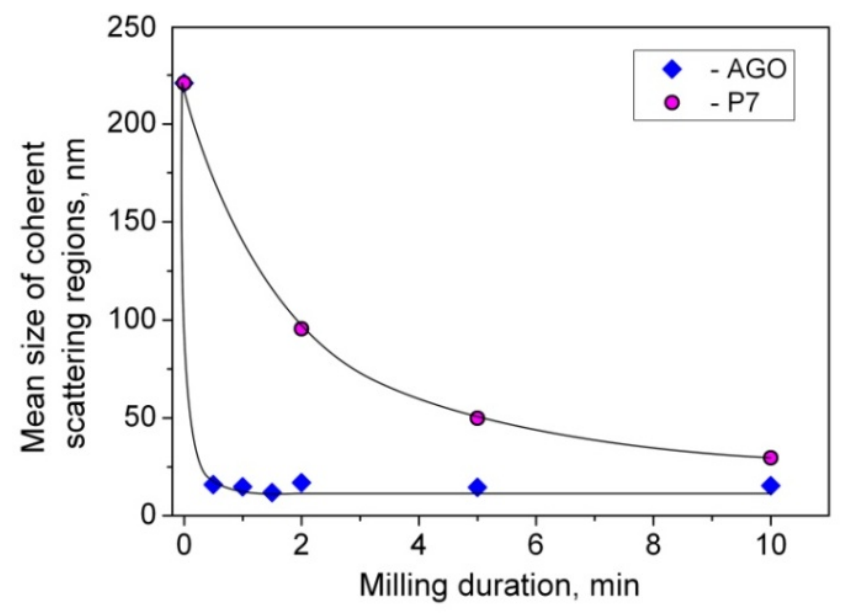

Figure 4. Change of the size of $x$-ray coherent scattering regions and microstrains for $\mathrm{NdMnO}_{3}$ mechanically activated in mills AGO-2 and PULVERISETTE 7.

Thus, it has been shown that mechanical activation in mills with the centrifugal factors from $9 \mathrm{~g}$ to $80 \mathrm{~g}$ produces nanostructured powders of manganites $\mathrm{LnMnO}_{3}(\mathrm{Ln}=\mathrm{Sm}$, $\mathrm{Nd})$. The mechanical activation in an AGO-2 type mill has been found to be the most effective as the nanoscale state is reached within 30 seconds of processing in it meanwhile microstrains and microstresses are still not big. The sample activated in an AGO-2 mill has microstrain of $0.25 \%$ and the CSR size of $\sim 20 \mathrm{~nm}$ whereas the same CSR size corresponds to the microstrain values of $0.59 \%$ and $061 \%$ for samples milled in PULVERISETTE 06-102 and PULVERISETTE 7 respectively. Injection of iron oxides to the material being processed is a feature of mechanical activation in an AGO-2 type mill.

It has been shown that mechanical treatment of the material in a mill PULVERISETTE 7 premium line is also quite effective. Nanostructured powder state is reached within 10 minutes. But in this case there are significant microstrain and microstresses that may be responsible for certain instability of the nanostructured state. The advantage of this mechanical activation method is relative purity of the material after processing.

\subsection{Surface States of Mechanoactivated Manganites}

Figure 5 presents XPS-spectra of manganese (Mn $2 p$ ), recorded on the original and mechanoactivated (in PULVERISETTE 06-102 for 7 hours) samples of $\mathrm{LaMnO}_{3}$. The binding energies of the electron level Mn $2 p$ (doublet $2 p_{3 / 2}, 2 p_{1 / 2}$ ) for the original lanthanum manganite are: 642.6 $\left(2 p_{3 / 2}\right)$ and $654.4 \mathrm{eV}\left(2 p_{1 / 2}\right)$. This corresponds to the state of manganese in hydrocarbon compounds, indicating the chemical degradation of the original sample. The spectral characteristics of the Mn $2 p$ electron level for mechanically activated $\mathrm{LaMnO}_{3}\left(642.1\left(2 p_{3 / 2}\right)\right.$ and $\left.653.7 \mathrm{eV}\left(2 p_{1 / 2}\right)\right)$ correspond to the multi-phase state: there are the basic oxide phase and the hydrocarbonate.

Characteristic XPS spectra of the original and mechanically activated (in AGO-2 mill) $\mathrm{NdMnO}_{3}$ samples are shown in Fig. 6. A complete set of spectral parameters is 
shown in Table 4.

Table 4. Structural characteristics of $\mathrm{NdMnO}_{3}$ samples milled in PULVERISETTE 06-102

$\begin{array}{ccc}\text { Sample } & \mathrm{Mn} 2 p_{3 / 2}(\mathrm{eV}) & \mathrm{O} 1 s\left(\mathrm{O}_{\mathrm{str}}\right) *(\mathrm{eV}) \\ \text { Original (AGO-0) } & 642.1 & 529.6 \\ \text { AGO, 1 min (AGO-1) } & 642.2 & 529.6 \\ \text { AGO, 1.5 } \min (\text { AGO-1.5) } & 642.8 & 529.7 \\ \text { AGO, } 5 \text { min (AGO-5) } & 642.2 & 529.7\end{array}$

* The binding energy of the line related to the structural oxygen of the basic compound
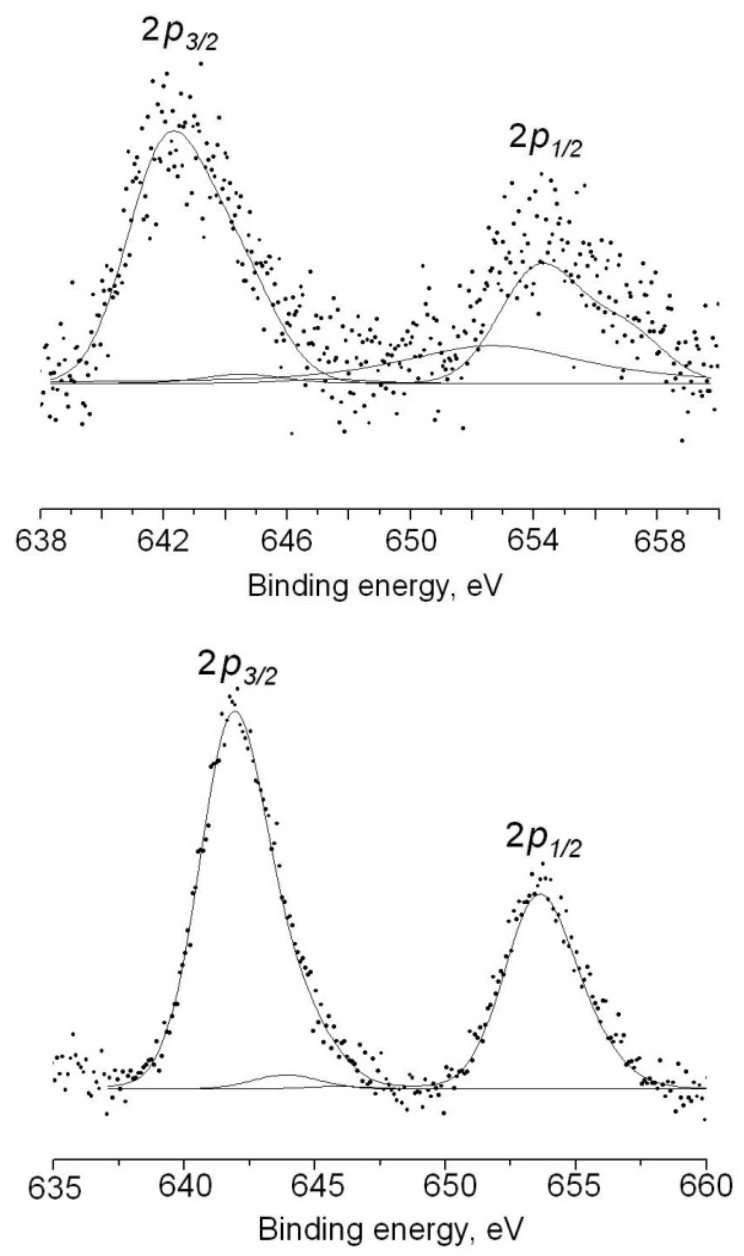

Figure 5. Mn $2 p$ spectrum of the original (upper) and mechanoactivated in PULVERISETTE 06-102 mill (lower) samples of $\mathrm{LaMnO}_{3}$.

In general, mechanical activation has not affected the state of the manganese and oxygen on the oxide surface. The binding energy of the line Mn $2 p_{3 / 2}$ for all samples is slightly increased relative to the state of $\mathrm{Mn}^{3+}$. Based on this, we can conclude the sample surface is contaminated by impurity phases. Increased concentration of hydrocarbonate compounds on the surface of the sample treated in AGO mill for $1.5 \mathrm{~min}$ has been observed.

The characteristic electronic spectra of the original and mechanically activated (in AGO mill) samples of $\mathrm{SmMnO}_{3}$ are presented in Fig. 7. Table 5 shows the numerical values of the characteristic spectral parameters of samarium manganite samples. We used the binding energy lines of $\mathrm{MnO}(\mathrm{OH})$ published in [23] when decomposed $\mathrm{O} 1 s$-spectrum of the sample activated in AGO mill for 5 $\min (\mathrm{AGO}-5)$.
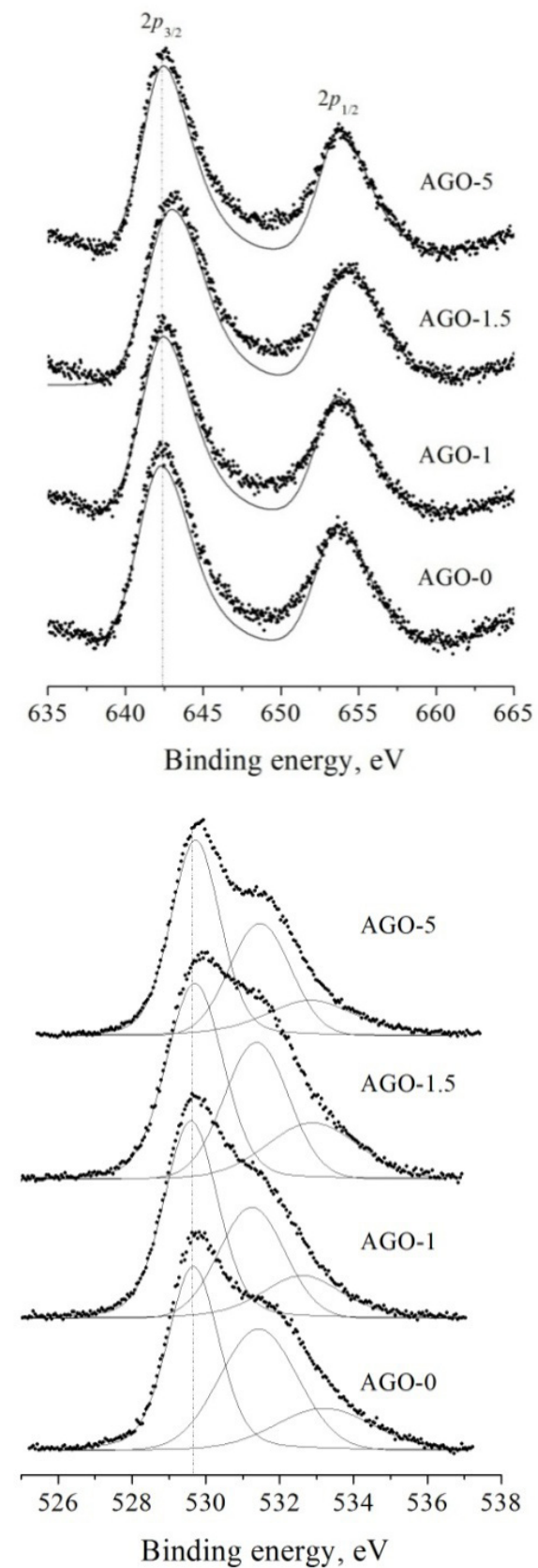

Figure 6. XPS spectra for $\mathrm{NdMnO}_{3}$ samples: $\mathrm{Mn}$ (2p) spectra (upper); O (1s) spectra (lower). Numbers in the notations of the curves correspond to the duration of mechanical treatment in AGO mill.

Table 5. Spectral characteristic parameters of $\mathrm{SmMnO}_{3}$ samples

$\begin{array}{ccc}\text { Sample } & \begin{array}{c}\mathrm{Mn} 2 p_{3 / 2} \\ (\mathrm{eV})\end{array} & \mathrm{O} 1 s\left(\mathrm{O}_{\text {str }}\right)(\mathrm{eV}) \\ \text { Original (AGO-0) } & 642.1 & 529.6 \\ \text { AGO, 0.5 min (AGO-0.5) } & 642.3 & 529.6 \\ \text { AGO, 2 min (AGO-2) } & 642.3 & 529.4 \\ \text { AGO, 5 min (AGO-5) } & 642.2 & 529.5\end{array}$



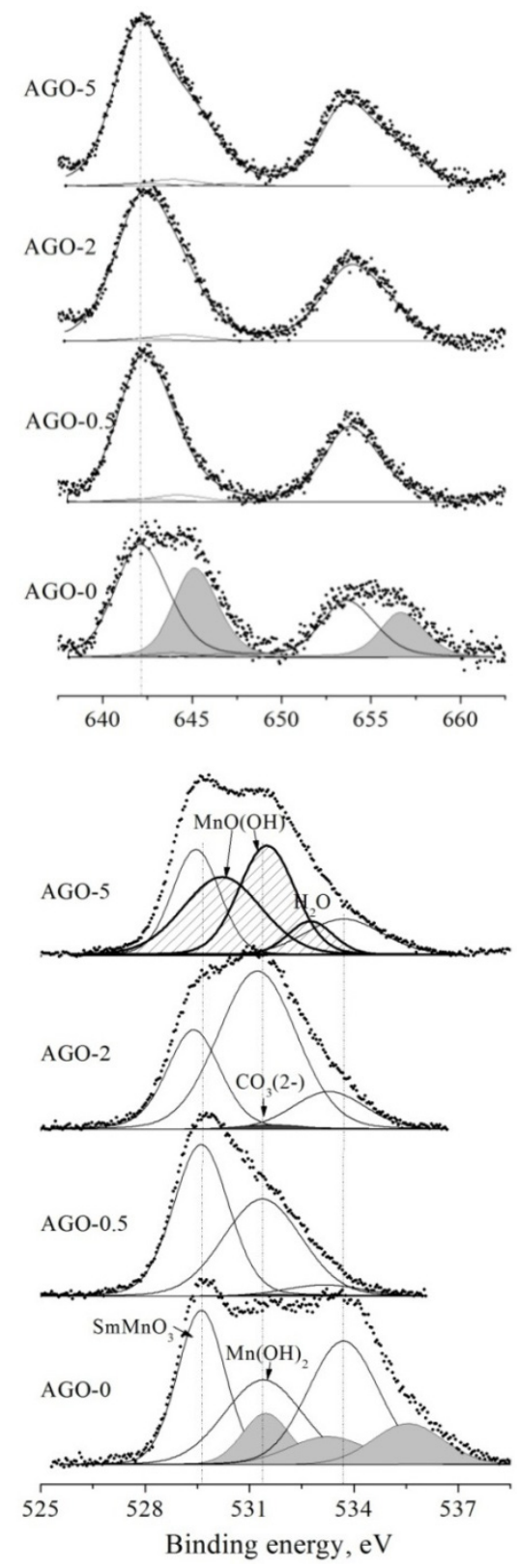

Figure 7. XPS spectra of the $\mathrm{SmMnO}_{3+\delta}$ electronic levels: $\mathrm{Mn} 2 p$ (upper), $\mathrm{O} 1 s$ (lower). The lines appeared in the spectra due to the effect of "double charging" are highlighted by tinting.

According to Table 5, the binding energies of Mn $2 p_{3 / 2}$ and $\mathrm{O} 1 s$ electron levels remain almost unchanged after mechanical activation. At the same time the portion of the oxygen peak related to the structure of $\mathrm{SmMnO}_{3+\delta}\left(\mathrm{O}_{\text {str }}\right)$ decreases (see Fig. 7, left), and the asymmetry degree of $2 p$-manganese lines significantly increases (Fig. 7, right). We can state that with increasing duration of mechanical activation (mainly over $0.5 \mathrm{~min}$ ) the amount of impurity phases on the surface of $\mathrm{SmMnO}_{3}$ increases. These impurities are products of the oxide decomposition proceeding under the influence of the atmospheric components: $\mathrm{H}_{2} \mathrm{O}$ and $\mathrm{CO}_{2}$. The main products of the interaction between the manganese oxide and an atmospheric air are hydroxide $\mathrm{Mn}(\mathrm{OH})_{2}$ and oxo-hydroxide
$\mathrm{MnOOH}$. For both the binding energy of O $1 s$ electron level of OH-groups at the level of $\sim 531.5 \mathrm{eV}$ and wider compared to oxide's the Mn $2 p$ doublet lines are representative.

Thus, the characteristics of the mill-activator and the nature of the material are essential factors of mechanical activation of $\mathrm{LnMnO}_{3}$ oxides ( $\left.\mathrm{Ln}=\mathrm{La}, \mathrm{Nd}, \mathrm{Sm}\right)$. When we use relatively soft iron balls (AGO-2 mill) the surface layer of the impurity phase growing under chemical action of atmospheric $\mathrm{CO}_{2}$ and $\mathrm{H}_{2} \mathrm{O}$ vapor on the material is not sufficiently subjected to effective scribing and fully (in case of $\mathrm{Ln}=\mathrm{Sm}$ ) or partially (when $\mathrm{Ln}=\mathrm{Nd}$ ) remains on oxide particles. But when we use ultrastrong $\mathrm{ZrO}_{2}$ balls (PULVERISETTE 06-102 mill) the surface of the oxide under treatment is rapidly cleaned.

\subsection{Cooperative Jahn-Teller Phase Transition}

The original samples of $\mathrm{SmMnO}_{3+\delta}$ and $\mathrm{NdMnO}_{3+\delta}$ had crystallographic parameters corresponding to the orbitally ordered phase, i.e. $(c / \sqrt{2}<a<b)$. Mechanical activation of the oxides led to a significant change of the Jahn-Teller distortion parameters. However, full suppression of the cooperative Jahn-Teller effect $(a<c / \sqrt{2}<b)$ was observed only on samples treated in the mill PULVERISETTE 06-102 for 10 hours (Fig. 8).

In order to determine the effect of mechanical activation of oxides $\mathrm{SmMnO}_{3+\delta}$ and $\mathrm{NdMnO}_{3+\delta}$ on the cooperative Jahn-Teller phase transition, high temperature diffraction studies were carried out on the original samples and samples treated in the mill AGO-2 for 30 seconds.

The Jahn-Teller transition from orbitally ordered $\mathrm{O}^{\prime}$-phase to orbitally disordered O-phase has been found in both the original and mechanically activated samples of $\mathrm{NdMnO}_{3}$.

During heating of the original sample, starting with a temperature of $700^{\circ} \mathrm{C}$ the intensity of the XRD-peaks of $\mathrm{O}^{\prime}$ -phase decreased, the peaks of O-phase appeared. A coexistence of the two phases with orthorhombic structure $\left(\mathrm{O}^{\prime}\right.$ and $\left.\mathrm{O}\right)$ took place in the temperature range of $700-750^{\circ} \mathrm{C}$. XRD- reflexes of $\mathrm{O}^{\prime}$-phase disappeared at $800^{\circ} \mathrm{C}$ and the only orbitally disordered phase of $\mathrm{NdMnO}_{3}$ with the unit cell parameters $a=0.5481(4) \mathrm{nm}, b=0,5569(4)$ $\mathrm{nm}, c=0,7759(6) \mathrm{nm}(a<c / \sqrt{2}<b)$ remained.

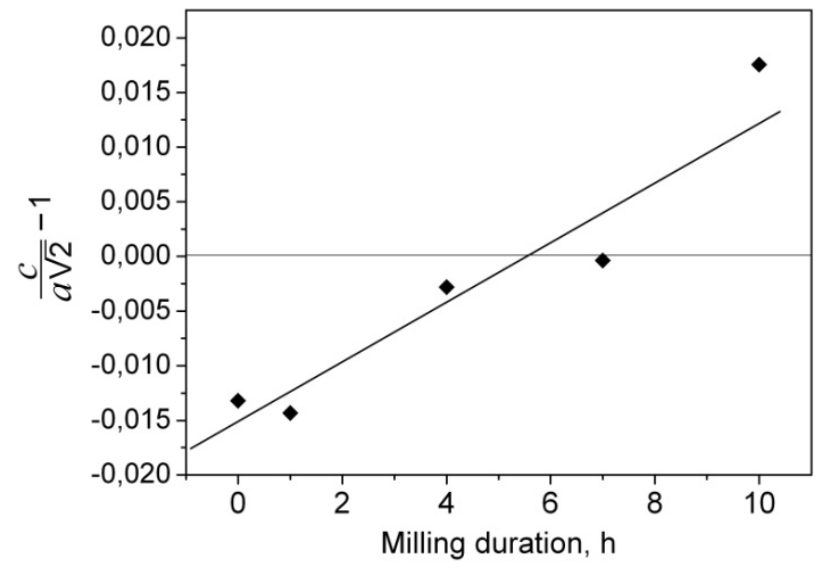

Figure 8. Ratio of the lattice parameters of $\mathrm{SmMnO}_{3}$ versus duration of mechanical treatment in PULVERISETTE 06-102 mill. 
Figure 9 presents the data of high-temperature measurements of crystallographic parameters for the original $\mathrm{NdMnO}_{3}$ and the sample treated in AGO-2 for 60 seconds. One can see the ratio $(c / a \sqrt{2}-1)$ changes its sign at the temperature $T_{1} \approx 800^{\circ} \mathrm{C}$ in the original oxide and at $T_{2} \approx$ $680^{\circ} \mathrm{C}$ in the mechanically activated sample.

At temperatures above $1000^{\circ} \mathrm{C}$, the existence of quasi-tetragonal phase is observed, i.e. $a=c / \sqrt{2}$. Moreover, the corresponding lattice parameters of the original and the mechanically activated sample become almost equal to each other.

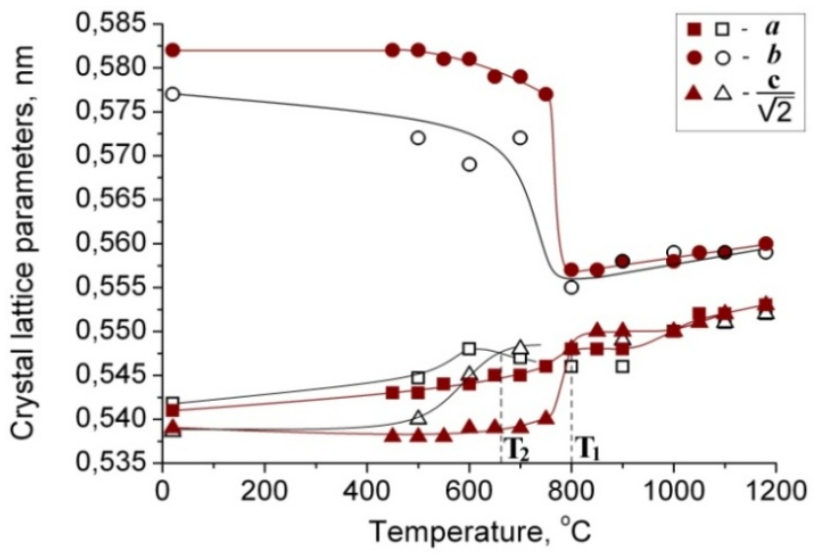

Figure 9. Temperature dependence of the crystal lattice parameters of the original (filled symbols) and the mechanically activated (empty symbols) samples of $\mathrm{NdMnO}_{3+\delta}$.

In the case of samarium manganite the temperature of the cooperative Jahn-Teller phase transition was higher by about $150^{\circ} \mathrm{C}$ compared with that for $\mathrm{NdMnO}_{3}$ (Fig. 10).

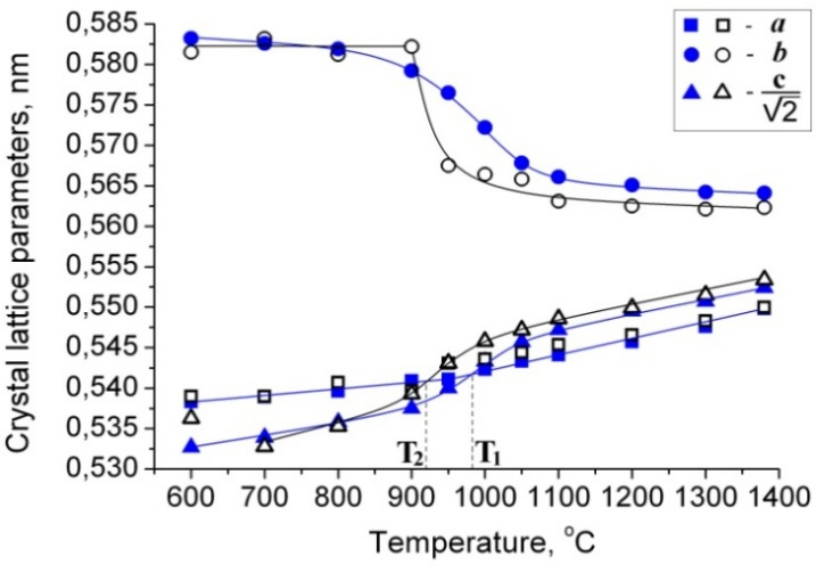

Figure 10. Temperature dependence of the crystal lattice parameters of the original (filled symbols) and the mechanically activated (empty symbols) samples of $\mathrm{SmMnO}_{3+\delta}$.

Upon heating above $950^{\circ} \mathrm{C}$, the ratio of the lattice parameters of the original $\mathrm{SmMnO}_{3+\delta}$ sample changed, the transition from orbitally ordered to orbitally disordered phase with the ratio of the lattice parameters $a<c / \sqrt{2}<b$ occurred. On further heating up to $1400^{\circ} \mathrm{C}$ this ratio did not change, i.e. high-temperature orbital disordering in $\mathrm{SmMnO}_{3+\delta}(\mathrm{O}$-phase) maintained.
Similar processes were observed on the mechanically activated sample. The influence of mechanical activation (as in the case of $\mathrm{NdMnO}_{3}$ ) resulted in a shift of the Jahn-Teller transition temperature to lower values $\left(900-940^{\circ} \mathrm{C}\right)$. The vertical dashed lines in Fig. 10 indicate the transition temperature $\mathrm{O}^{\prime} \rightarrow \mathrm{O},\left(T_{1}-\right.$ for the original, $T_{2}$ - for the mechanically activated sample).

\subsection{Interaction of the Oxides with Atmospheric Gas Phase}

To study the interactions of the oxides with atmospheric gas phase a thermal analysis of the original samples and samples treated in all three types of activators was carried out.

Effect of mechanical activation duration on the kinetics of the interaction between $\mathrm{LnMnO}_{3+\delta}$ oxides and gas atmosphere are shown in Fig. 11,12 on an example of thermogravimetric (TGA) analysis and differential scanning calorimetry (DSC) data for $\mathrm{NdMnO}_{3+\delta}$.

The intensity of these processes in dependence of the processing mode (activator type) is illustrated in Fig. 13 and Fig. 14 by TG and DSC data for the following samples of $\mathrm{SmMnO}_{3+\delta}: 1$ - original, 2 - treated in AGO-2 mill for 60 seconds, 3 - processed in PULVERISETTE 06-102 mill for 7 hours, 4 - treated in PULVERISETTE 7 premium line mill for 10 minutes. Selected mechanically activated samples had similar values of average size of coherent scattering regions (about $20 \mathrm{~nm}$ ) and microstrain (about $0.65 \%$ ).

At the first stage of heating (up to $300-400^{\circ} \mathrm{C}$ ), all samples (except the original $\mathrm{SmMnO}_{3}$ ) demonstrate the weight loss (Fig. 11, 13), which is associated with the removal of water and adsorbed gases (physical desorption).

When heated above $300-400^{\circ} \mathrm{C}$, all mechanoactivated $\mathrm{NdMnO}_{3}$ samples show the weight gain associated with the absorption of oxygen from the gaseous medium. Oxidation of the original $\mathrm{NdMnO}_{3}$ is slight and it occurs in the temperature range of $700-950^{\circ} \mathrm{C}$. In the case of mechanically activated samples, this process starts earlier and proceeds more intensively, including due to more developed surface. The corresponding exothermic effect overlaps with the endothermic peak related to Jahn- Teller phase transition. One can see from Fig. 9 and DSC curves on Fig. 12 the reduction process of the phase transition from JT orbitally ordered $\mathrm{O}$ '-phase to orbitally disordered O-phase (with a distinct endothermic effect) in this temperature range already takes place.

These oxidation processes should be interrelated with the destruction of the Jahn-Teller ordering in the oxide. Every extra oxygen ion leads to the disappearance of the two JT ions by the reaction:

$$
\left.2 \mathrm{Mn}^{3+}+\frac{1}{2} \mathrm{O}_{2}(\text { gas })=2 \mathrm{Mn}^{4+}+\mathrm{O}^{2-} \text { (crystal. }\right)
$$

Therefore, the JT ordering prevents additional oxidation at low temperatures. When the temperature increases the gain in the free energy of an oxide due to the cooperative Jahn-Teller ordering decreases the oxidation process begins. 


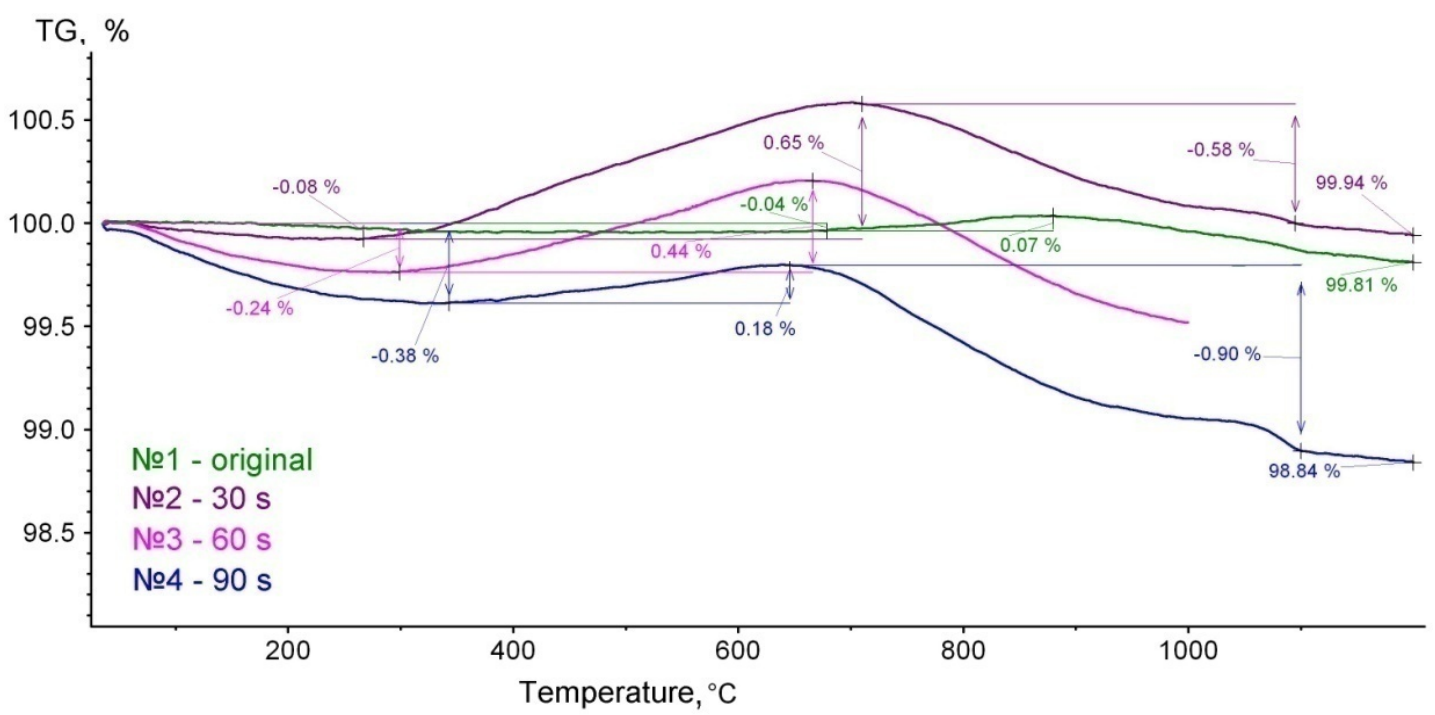

Figure 11. Thermogravimetric data on the original and mechanoactivated in $\mathrm{AGO}-2$ samples of $\mathrm{NdMnO}_{3}$ at heating rate of $10^{\circ} \mathrm{C} / \mathrm{min}$.

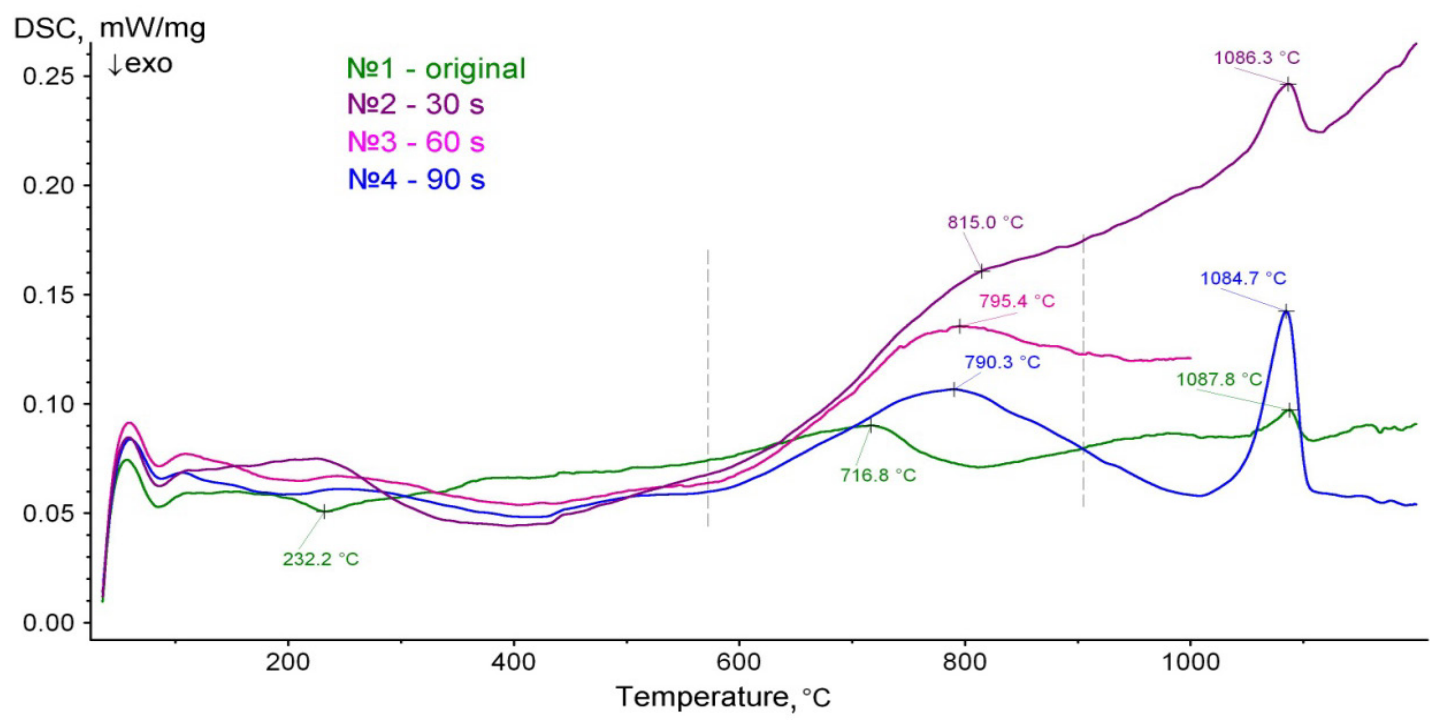

Figure 12. Calorimetry data on the original and mechanoactivated in AGO-2 samples of $\mathrm{NdMnO}_{3}$.

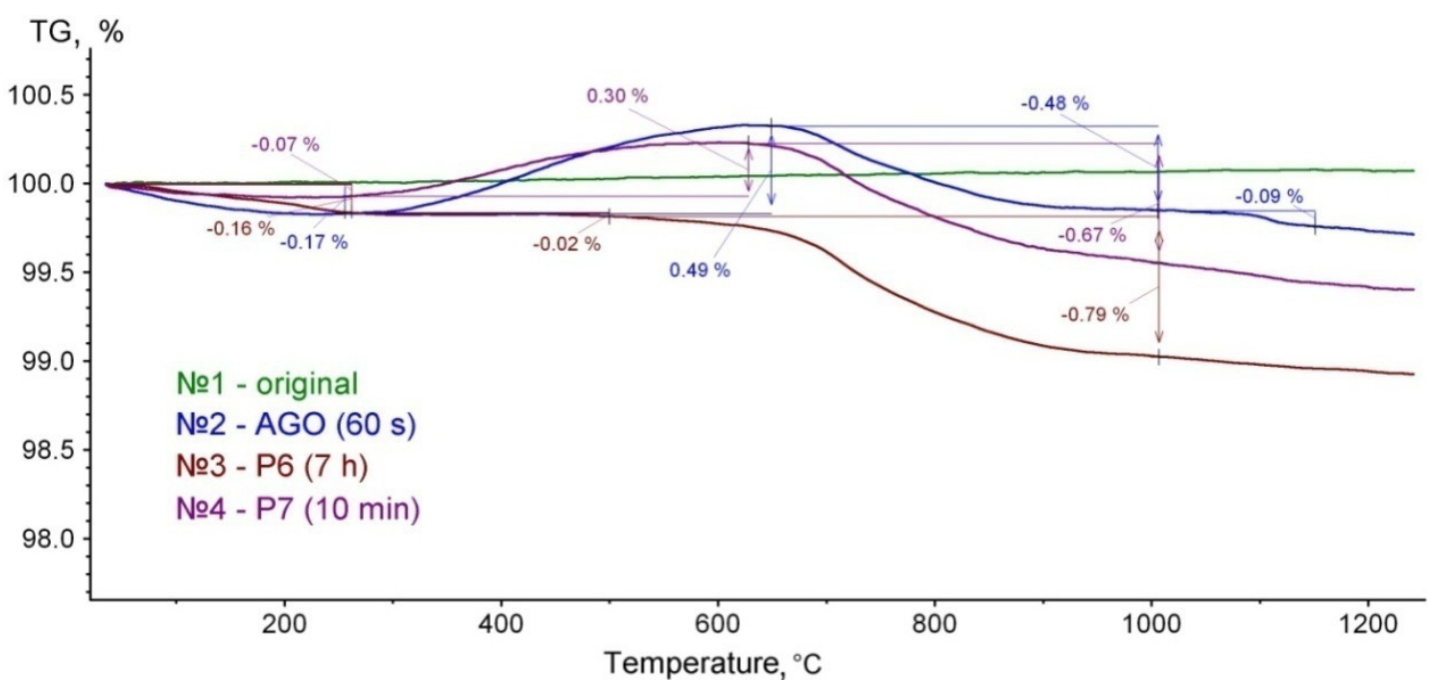

Figure 13. Thermogravimetric data on $\mathrm{SmMnO}_{3}$ at heating rate of $10^{\circ} \mathrm{C} / \mathrm{min} .1$ - the original sample, 2 - treated in AGO-2 for 60 seconds, 3 - treated in PULVERISETTE 06-102 (P6) for 7 hours, 4 - treated in PULVERISETTE 7 premium line (P7) for 10 minutes. 


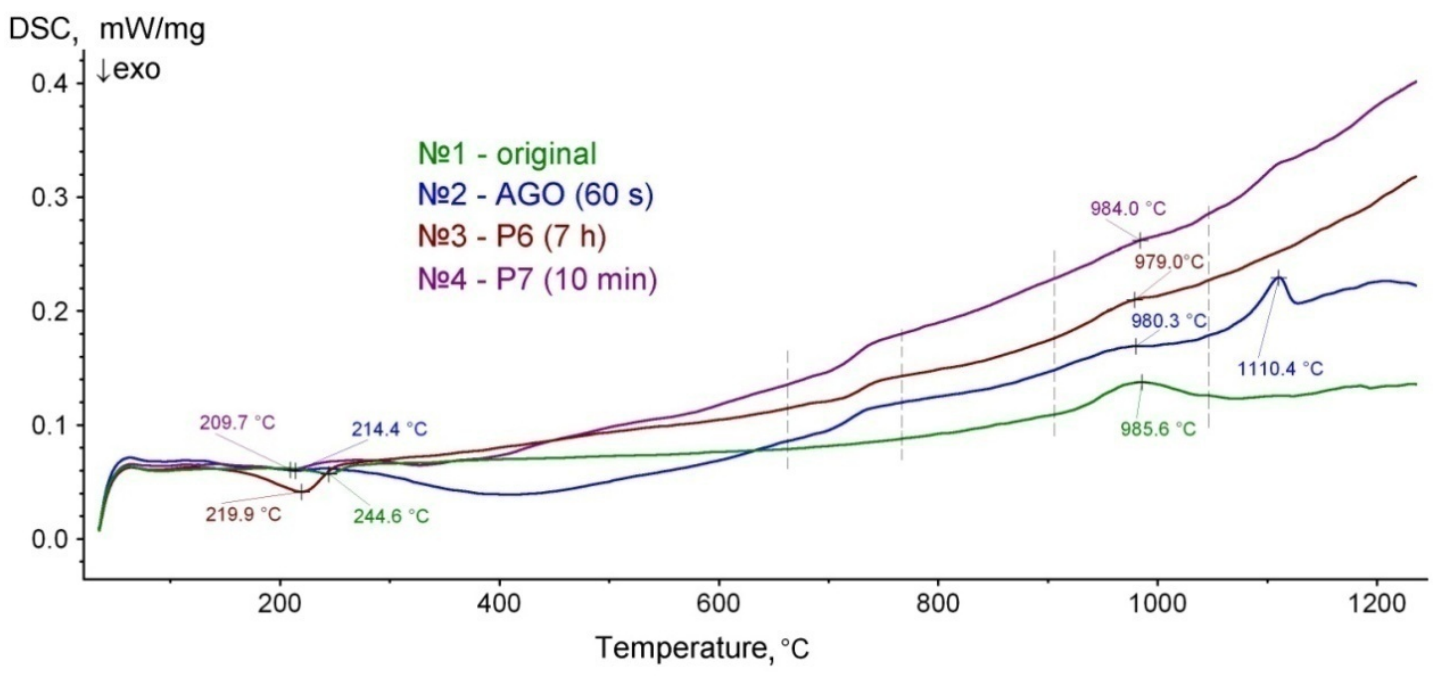

Figure 14. Thermograms of $\mathrm{SmMnO}_{3}$ samples upon heating up to $1200^{\circ} \mathrm{C}$ in a stream of air at heating rate of $10^{\circ} \mathrm{C} / \mathrm{min} .1-$ the original sample, $2-$ treated in AGO-2 for 60 seconds, 3 - treated in PULVERISETTE 06-102 (P6) for 7 hours, 4 - treated in PULVERISETTE 7 premium line (P7) for 10 minutes.

In accordance with the theoretical point of view and XRD data the respective thermodynamic values including the phase transition temperature in mechanically activated powders should be lower and so the oxidation process must start earlier.

Clearly defined narrow endothermic peak at $1088^{\circ} \mathrm{C}$ of the original sample and at $1085-1086^{\circ} \mathrm{C}$ of mechanically activated samples (Fig. 12) is consistent with the high-temperature XRD data and associated with the transition to quasi-tetragonal phase (Fig. 9). This transition is more pronounced in the mechanically activated samples. The calorimetric effect is accompanied by a little mass loss manifested in the form of a step in the TG curve.

One can see from Fig. 14 that only one calorimetric effect - an endothermic peak in the temperature range of $950-1020^{\circ} \mathrm{C}$ is observed on the thermogram of the original sample $\mathrm{SmMnO}_{3}$. It corresponds to the Jahn-Teller transition from $\mathrm{O}^{\prime}$ - to O-phase and it's not accompanied by change in mass (Fig. 13). A similar peak of mechanically activated samples is shifted to lower temperatures. Changing the peak shape of the latter compared with that for the original $\mathrm{SmMnO}_{3}$ sample is due to a significant change in the parameters of the Jahn-Teller distortion after mechanical activation. In the sample treated in PULVERISETTE 06-102 for 7 hours, the effect is hardly noticeable, that can be explained by close to zero value of the ratio $(c / a \sqrt{2}-1)$ (Fig. 8).

In contrast to the original sample, mechanically activated $\mathrm{SmMnO}_{3}$ samples have TG curves which exhibit an initial mass gain with increasing temperature above $350^{\circ} \mathrm{C}$, achieving its maximum at $600-650^{\circ} \mathrm{C}$ and then a monotonic decrease in mass. Similar phenomena have been observed on mechanically activated $\mathrm{NdMnO}_{3+\delta}$ oxides. They are associated with different manifestations of varying size effects and non-stoichiometry. The latter play an important role in the structural phase transitions of the first kind: the Jahn-Teller transition from the orbitally-ordered $\mathrm{O}^{\prime}$-phase to orbitally disordered O-phase and concomitant phase separation of non-stoichiometric system to "high-temperature" and "low-temperature" Jahn-Teller phases. The exception is the sample treated in the mill PULVERISETTE 06-102 for 7 hours (№ 3 on Fig.13, 14), which had the highest oxygen non-stoichiometry after grinding. Heating of this sample could not lead to additional oxidation, as evidenced by its weight loss comparable with that of other mechanoactivated samples at temperatures above $600^{\circ} \mathrm{C}$.

High-temperature process with well-defined endothermic peak at $1110^{\circ} \mathrm{C}$ is observed on the samples pre-treated in high energy AGO-2 and P7 mills (Fig. 14). Moreover, a mass loss manifested as a step down on TG curve and the corresponding DSC effect are more pronounced on the sample activated in AGO-2. We cannot conclude this process is associated with the transition to quasi tetragonal phase as in the case of $\mathrm{NdMnO}_{3}$, mentioned above. According to the high-temperature XRD data of $\mathrm{SmMnO}_{3}$ (Fig. 10) the equality $a=c / \sqrt{2}$ is not achieved at temperatures up to $1400^{\circ} \mathrm{C}$. Either the thermal analysis conditions (heating rate, temperature range) did not allow recording the transition to quasi tetragonal phase in $\mathrm{SmMnO}_{3}$ samples or the observed effect is related to another reduction process. Difference in behavior of the samples activated in AGO-2 and P7 mills on one side and the original and treated in P6 mill samples on the other side can be explained by the fact the mechanical activation in high-energy mills promotes destruction of the orthorhombic phase.

\subsection{Oxygen Isotope Exchange}

In this part of the work we present oxygen isotope exchange (OIE) data for the mechanoactivated oxides under consideration. For comparison, the OIE studies were also performed on the original micropowders. The oxides $\mathrm{LnMnO}_{3+\delta}$ are a convenient model object for optimization of the OIE technique on nanopowders [22]. The oxygen volume diffusion coefficients in milled powders change slightly by 
comparison with those of the bulk oxides [24].

\subsection{1. $\mathrm{LaMnO}_{3+\delta}$.}

The OIE study was performed on the original sample of $\mathrm{LaMnO}_{3+\delta}$ and the sample mechanically activated in PULVERISETTE 06-102 for 13 hours [5]. According to X-ray diffraction data, the milled powder had an orthorhombic structure with the average size of coherent scattering domains of about $15 \mathrm{~nm}$.

Experimental and calculated $C(t)$ dependences for the milled $\mathrm{LaMnO}_{3+\delta}$ powder are given in Fig. 15. The experimental data have been processed using traditional OIE scenarios for systems with low oxygen volume diffusion coefficients.

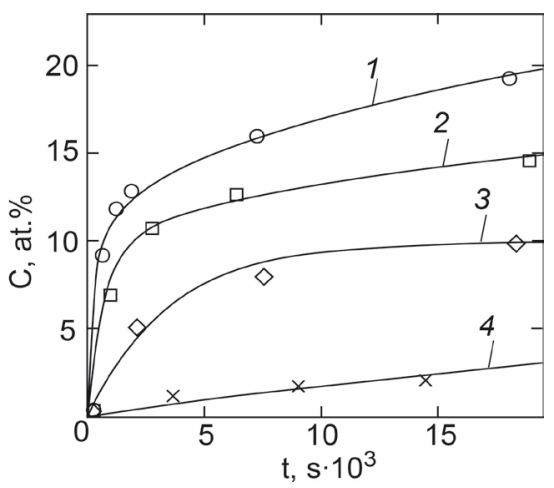

Figure 15. $C(t)$ dependences for the milled $\mathrm{LaMnO}_{3+\delta}$ powder: $1-560^{\circ} \mathrm{C}$; $2-500^{\circ} \mathrm{C} ; 3-400^{\circ} \mathrm{C} ; 4-300^{\circ} \mathrm{C}[2]$. Dots - experimental data; lines calculation.

It turned out that the experimental dependences $C(t)$ are not described in terms of diffusion theoretical models assuming no surface energy barrier during isotope exchange. In relaxation models (isotope exchange on the oxide surface), satisfactory fit with experimental data was shown only for low temperatures $\left(300\right.$ and $\left.400^{\circ} \mathrm{C}\right)$. For elevated temperatures $\left(500\right.$ and $\left.560^{\circ} \mathrm{C}\right)$, the best fit with experimental data was achieved in the model for simultaneous relaxation and diffusion.

The temperature dependences of the values of isotope exchange frequency at the surface $\Gamma$ which provided satisfactory fit with experimental dependences $C(t)$ were described with the Arrhenius expression for the frequency factor $\Gamma_{0}=\left(0.97 \cdot 10^{3} \pm 0.70 \cdot 10^{3}\right) \mathrm{s}^{-1}$ and the activation energy $E=(0.88 \pm 0.07) \mathrm{eV}$. The oxygen volume diffusion coefficients $D$ obtained from $C(t)$ dependences have the following values: $D\left(560^{\circ} \mathrm{C}\right)=1.35 \cdot 10^{-19} \mathrm{~cm}^{2} / \mathrm{s} ; D\left(500^{\circ} \mathrm{C}\right)=$ $3.55 \cdot 10^{-20} \mathrm{~cm}^{2} / \mathrm{s}$.

Figure 16 demonstrates experimental $C(t)$ dependences for $\mathrm{LaMnO}_{3+\delta}$ micropowder. It is seen the size factor has shown up very vividly: the concentrations of ${ }^{18} \mathrm{O}$ isotopes in the micropowder are tens times lower.

These results show that the technique for OIE examination on oxide nanopowders proposed in the work [2] is consistent. It furnishes information about nanopowder dimensional characteristics, reaction rates on the oxide particles surface during isotope exchange, and oxygen volume diffusion coefficients in oxides.

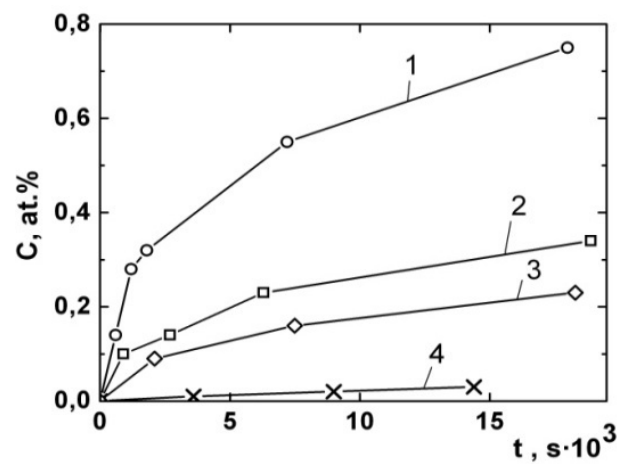

Figure 16. Experimental dependences $C(t)$ for $\mathrm{LaMnO}_{3+\delta}$ micropowder: 1 $-560^{\circ} \mathrm{C} ; 2-500^{\circ} \mathrm{C} ; 3-400^{\circ} \mathrm{C} ; 4-300^{\circ} \mathrm{C}[2]$.

\subsection{2. $\mathrm{NdMnO}_{3+\delta}$.}

According to X-ray diffraction studies the phase composition of the milled (in AGO-2) and the original powders remained unchanged upon heating in air in the range $400-500^{\circ} \mathrm{C}$. In this temperature range the average size of CSR varied slightly. Experimental $C(t)$ dependences of the average concentration of ${ }^{18} \mathrm{O}$ isotope in the powders as function of annealing time for the original and the milled $\mathrm{NdMnO}_{3+\delta}$ powders are depicted in Fig. 17 (for $400^{\circ} \mathrm{C}$ ) and Fig. 18 (for $500^{\circ} \mathrm{C}[6]$ ). One can see that the concentration of ${ }^{18} \mathrm{O}$ increases with annealing time at each temperature.

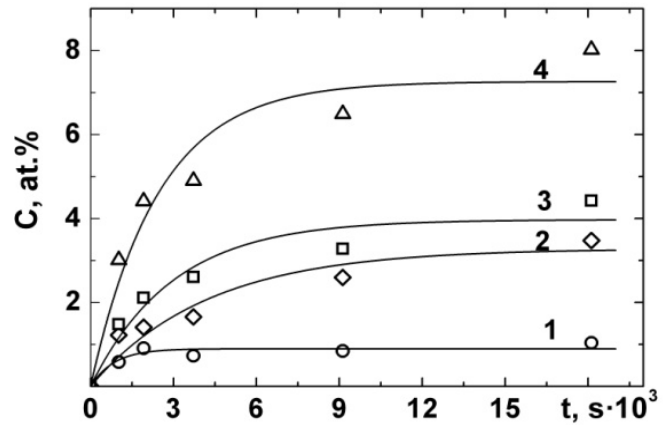

Figure 17. $C(t)$ dependences for the original (1) and the milled $\mathrm{NdMnO}_{3+\delta}$ powders (2-4) at $400^{\circ} \mathrm{C}$. Milling duration: $30 \mathrm{~s} \mathrm{(curve} \mathrm{2),} 60 \mathrm{~s}$ (3), $300 \mathrm{~s}(4)$

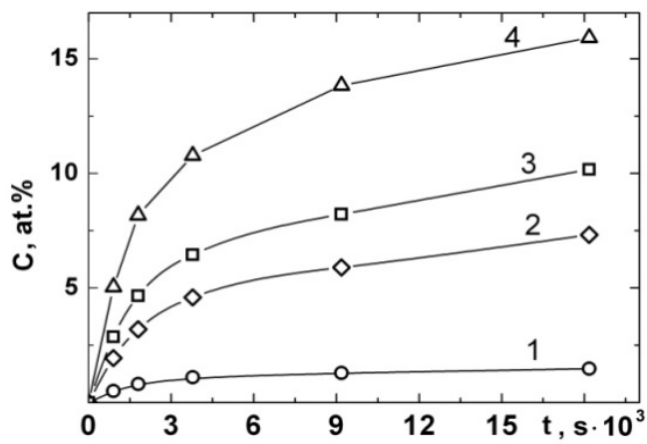

Figure 18. $C(t)$ dependences for the original (1) and the milled $\mathrm{NdMnO}_{3+\delta}$ powders (2-4) at $500^{\circ} \mathrm{C}$. Milling duration: $30 \mathrm{~s}$ (curve 2), $60 \mathrm{~s}$ (3), $300 \mathrm{~s} \mathrm{(4).}$

One can see from Figs. 15 and 16 that as a result of grinding the concentration of ${ }^{18} \mathrm{O}$ isotope in the powders 
increased. The values of the concentration $C(t)$ at $500^{\circ} \mathrm{C}$ were higher than at $400^{\circ} \mathrm{C}$.

Experimental dependences $C(t)$ at $400^{\circ} \mathrm{C}$ presented in Fig. 17 are processed using the isotope exchange model, in which only oxygen ions from the external atomic layer of the oxide particle participate. In this case we have "relaxation" type dependences $C(t)$ for powders [24-27]

$$
C(t)=C_{0} \frac{3 \Delta}{r}(1-\exp (-\Gamma t))
$$

where $C_{0}=c \mu, c$ is the atomic concentration of oxygen in the oxide, $\mu$ is the fraction of ${ }^{18} \mathrm{O}$ isotope in gaseous oxygen, $\Delta$ is the monolayer thickness in the oxide (it is a theory parameter), $r$ is the particle radius. Such description suggests that the average diffusion path $l=2(D t)^{1 / 2}$, associated with bulk diffusion, must be less than or of order $\Delta$. The value $\Delta=$ $0.5 \mathrm{~nm}$ was assumed in the calculations. Frequencies $\Gamma$ measured in OIE experiments and presented in Table 6 determine the oxygen exchange rate between the gaseous phase and the surface of the oxide powder.

Table 6. Isotope exchange parameters of $\mathrm{NdMnO}_{3+\delta}$ powders

$\begin{array}{ccc}\text { Sample } & \begin{array}{c}\Gamma\left[400^{\circ} \mathrm{C}\right], \\ \left(\mathrm{s}^{-1}\right)\end{array} & \begin{array}{c}D\left[500^{\circ} \mathrm{C}\right], \\ \left(\mathrm{cm}^{2} / \mathrm{s}\right)\end{array} \\ \text { Original } & 1.2 \cdot 10^{-3} & - \\ \text { AGO, } 0.5 \mathrm{~min} & 2.4 \cdot 10^{-4} & 2.1 \cdot 10^{-19} \\ \text { AGO, } 1 \mathrm{~min} & 3.4 \cdot 10^{-4} & 3.5 \cdot 10^{-19} \\ \text { AGO, } 5 \mathrm{~min} & 4.1 \cdot 10^{-4} & 2.5 \cdot 10^{-19}\end{array}$

A nontrivial dependence was observed between the isotope exchange frequency $\Gamma$ and the milling duration: it was maximal for the micropowder and minimal for the least milling duration. This nonmonotonic dependence can be due to a variation in the chemical composition of the outer atomic layer of powder particles during mechanical activation.

The data on OIE for mechanically activated oxides $\mathrm{NdMnO}_{3+\delta}$ and $\mathrm{LaMnO}_{3+\delta}$ at $400^{\circ} \mathrm{C}$ agree with each other in the following respect: they are satisfactorily described with Eq.1, in which oxygen atom diffusion in the bulk of the particles is neglected [2].

The OIE results at $500^{\circ} \mathrm{C}[26]$ were described in the model allowing for diffusion of oxygen atoms in oxide particles (see Fig. 19).

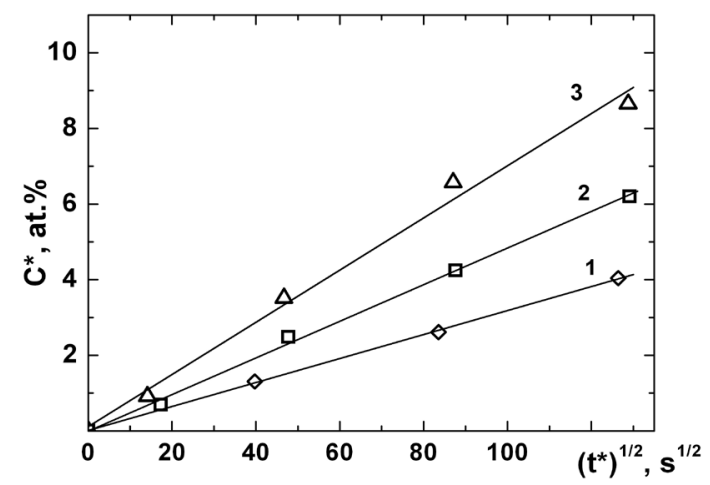

Figure 19. Diffusion type of $C(t)$ dependences for milled powders at $500^{\circ} \mathrm{C}$ according to Eq. 2, points are experimental data. Milling duration: 30 $\mathrm{s}$ (curve 1), $60 \mathrm{~s}(2)$ and $300 \mathrm{~s} \mathrm{(3)}$
The $C(t)$ dependences for $500^{\circ} \mathrm{C}$ were processed with the following expression [28]:

$$
C^{*}\left(t^{*}\right)=C_{0} \frac{6}{r}\left(1-\frac{3 \Delta}{r} \sqrt{\frac{D t^{*}}{\pi}}\right), \quad \frac{C(t)}{C_{0}}<0.3,
$$

where $D$ is the coefficient of bulk diffusion of oxygen atoms. It is assumed that the equilibrium concentration of tracer atoms during annealing in the outer layer is achieved for an infinitely small time. This condition was not fulfilled in our experiments; therefore, instead of $C$ and $t$, we introduced $C^{*}$ and $t^{*}$ into Eq. 2. This substitution means that the values $C^{*}=0$ and $t^{*}=0$ correspond to the conditions, when the equilibrium concentration of ${ }^{18} \mathrm{O}$ atoms is reached in the outer layer of the oxide particle. It was found that $t^{*} \approx 30 \mathrm{~min}$.

In Fig. 19 one can see that the dependences of $C^{*}$ on $\sqrt{t^{*}}$ are linear, which is indicative of the diffusion mechanism of changes in the average concentration of ${ }^{18} \mathrm{O}$ isotope in mechanically activated powders for the annealing time $t>t^{*}$.

The obtained values of the diffusion constants at $500^{\circ} \mathrm{C}$ are listed in the Table 1 . The diffusion length $2(D t)^{1 / 2}$ in our experiments was $\leq 1 \mathrm{~nm}$. The spread of the $D$ values was about 1.5 times. This value is admissible when very low values of diffusion coefficients are measured. Thus, there is a reason to believe that the average value of the diffusion constant $D$ is $3 \cdot 10^{-19} \mathrm{~cm}^{2} / \mathrm{s}$ at $500^{\circ} \mathrm{C}$. The value of $D$ in the oxide $\mathrm{NdMnO}_{3+\delta}$ is approximately an order of magnitude higher than in related oxides based on lanthanum manganite.

In addition to the considered results the data on bulk diffusion in the original powder of $\mathrm{NdMnO}_{3+\delta}$ oxide were obtained for temperatures of 600 and $700^{\circ} \mathrm{C}$. The corresponding isotherms of $C(t)$ dependencies are shown in Fig. 20.

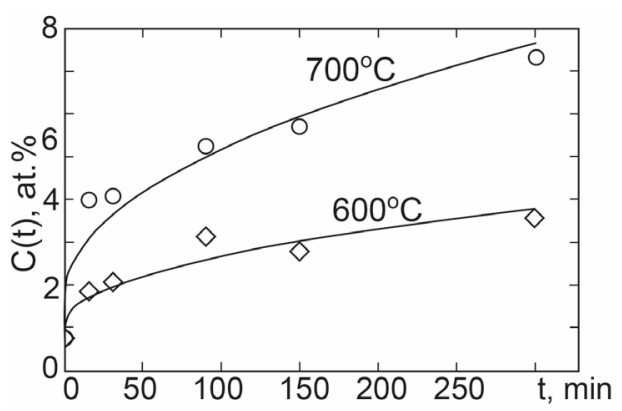

Figure 20. $C(t)$ dependences for the original powders of $\mathrm{NdMnO}_{3+\delta}$ at $600^{\circ} \mathrm{C}$ and $700^{\circ} \mathrm{C}$ : points - the experimental data, lines - the results of calculations.

The traditional diffusion model for their description was used:

$$
\begin{gathered}
C(t)=C_{0}\left(1-\frac{3 \Delta}{r}\right)\left(1-\frac{6}{\pi^{2}} \sum_{s=1}^{\infty} \frac{1}{S^{2}} \exp \left(-\left(\frac{s \pi}{r}\right)^{2} D t\right)\right)+ \\
+C_{0} \frac{3 \Delta}{r}
\end{gathered}
$$

The temperature dependence of the diffusion coefficients 
obtained by taking into account all the diffusion data for the original and milled samples is shown in Fig. 21.

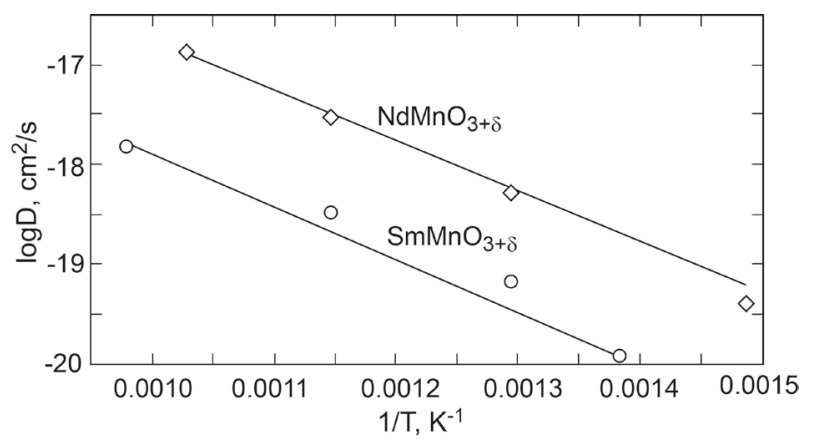

Figure 21. The temperature dependence of the oxygen diffusion coefficients in $\mathrm{NdMnO}_{3+\delta}$ and $\mathrm{SmMnO}_{3+\delta}$ oxides

These results demonstrate the existence of a "low-temperature" region of the impurity diffusion activation energy of $Q \cong 1 \mathrm{eV}$ and the concentration of oxygen vacancies $C_{V} \cong 10^{-12}$.

\subsection{3. $\mathrm{SmMnO}_{3+\delta}$}

Investigations of isotopic exchange for the two types of samples - the original powders and subjected to grinding for one minute in a mill AGO-2 are performed. As for the previously studied rare-earth manganites the isotope exchange rate in mechanically activated $\mathrm{SmMnO}_{3+\delta}$ oxides is several times higher than that of the original powder. It is shown that even at relatively low temperatures $\left(450-470^{\circ} \mathrm{C}\right)$ annealing of the mechanoactivated samples in an atmosphere of ${ }^{18} \mathrm{O}_{2}$ an active process of replacing ${ }^{16} \mathrm{O}$ to ${ }^{18} \mathrm{O}$ atoms occurs with the bulk diffusion participation (Fig.22(a)). The possibility of separating the effects associated with isotopic exchange at the surface and diffusion processes was demonstrated (Fig. 22(b)).

Some variants of the isotope exchange experiments capable of measuring the diffusion coefficients of oxygen tracer at relatively low temperatures were tested. They are associated with the creation of the permanent ${ }^{18} \mathrm{O}_{2}$ source condition on grain boundaries during prolonged low-temperature annealing in an atmosphere of ${ }^{18} \mathrm{O}_{2}$ or brief annealing at a temperature higher than that of the diffusion studies. As a result, the parameters that characterize the bulk oxygen diffusion in the mechanically activated $\mathrm{LnMnO}_{3+\delta}$ $(\mathrm{Ln}=\mathrm{Sm}, \mathrm{Nd})$ powders were determined (See Fig. 21). It was shown that the activation energy $Q$ for diffusion in considered temperature range comes to approximately $1 \mathrm{eV}$. This value of $Q$ and the pre-exponential factor order of magnitude $\left(D_{0} \sim 10^{-12} \mathrm{~cm}^{2} / \mathrm{s}\right)$ point directly to the impurity diffusion mechanism, i.e. the oxygen diffusion on structural vacancies.

Thus, for $\mathrm{LnMnO}_{3+\delta}$ oxides the dependence between the oxygen isotope exchange kinetics and the duration of mechanical activation was established. When the milling duration increased, the concentration of ${ }^{18} \mathrm{O}$ isotope in the powders grew. The frequency of isotope exchange between gaseous oxygen ${ }^{18} \mathrm{O}$ and oxide powders depended non-monotonically on the milling duration. A procedure for measuring low values of oxygen diffusion coefficients was proposed. The methodological prospects of the described procedure were demonstrated. The established low values of diffusion coefficients cannot be determined by other procedures oriented at measurements of concentration profiles of tracer atoms.
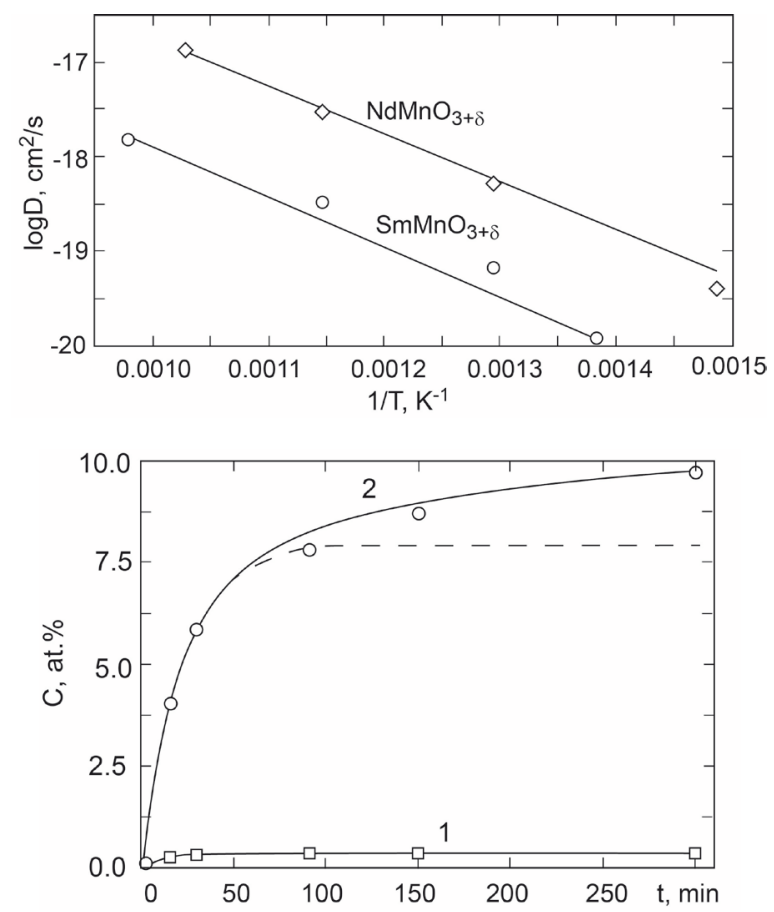

Figure 22. $C(t)$ dependences for the original and milled powders of $\mathrm{SmMnO}_{3+\delta}$ (upper). The ${ }^{18} \mathrm{O}$ content dependence in $\mathrm{SmMnO}_{3+\delta}$ powders on the annealing duration in an atmosphere ${ }^{18} \mathrm{O}_{2}$ at $470^{\circ} \mathrm{C}$ (lower): 1- the original powder, 2 - mechanoactivated for 60 seconds in a mill AGO-2. The dashed lines show the isotope exchange stages associated with the surface processes and bulk diffusion.

\section{Conclusion}

The surface states, structure, peculiarities of phase transitions and kinetic processes (oxidation, reduction, isotope exchange) in mechanically activated oxides $\mathrm{LnMnO}_{3}$ $(\mathrm{Ln}=\mathrm{Sm}, \mathrm{Nd}, \mathrm{La})$ have been studied.

Features of samples milled in different types of activators have been found. The advantages and disadvantages of various activator mills in obtaining nanopowders of manganites have been shown. Mechanical activation in an AGO-2 type mill has been found to be the most effective. However, we could not get a nanopowder with the average particle size less than $14 \mathrm{~nm}$ even under long milling. This reflects the limitation of mechanical grinding method in producing nanopowders: the real nanoscale $(\sim 5 \mathrm{~nm})$ cannot be always achieved [18-19]. Prolonged mechanical activation was found to may lead to the complete suppression of the cooperative Jahn-Teller effect at the room temperature.

The obtained results on phase transformation in the 
manganites under consideration complement (qualitatively and quantitatively) literature data. The temperature of the phase transition caused by cooperative Jahn-Teller effect for macro- and microcrystalline $\mathrm{NdMnO}_{3}$ and $\mathrm{SmMnO}_{3}$ manganites have been refined related to data [29], whereas the corresponding temperature ranges for mechanically activated samples of $\mathrm{NdMnO}_{3}$ and $\mathrm{SmMnO}_{3}$ have been determined for the first time.. Mechanical processing has been shown to cause a significant change of Jahn-Teller distortion parameters and temperatures of the transition from orbitally-ordered $\mathrm{O}^{\prime}$ - to orbitally disordered O-phase. The presence of connection between redox processes and destruction of orbital ordering in the oxides has been demonstrated.

The oxidation of mechanically activated samples has been demonstrated to be much more intense than that of the original manganites. The oxidation process is shifted to lower temperatures compared to the original samples and takes place over a much wider temperature range.

The data on the rates of surface reactions during isotope exchange and oxygen self-diffusion coefficients have been obtained. The results on isotopic exchange in mechanically activated powder of $\mathrm{SmMnO}_{3+\delta}$ and $\mathrm{NdMnO}_{3}$ are unique as relevant studies of these oxides have not been conducted yet. It has been shown that the rate of isotope exchange with the gas phase and the ${ }^{18} \mathrm{O}$ isotope content in mechanically activated powders is several times higher than that in the original samples. Even in case of relatively low annealing temperature $\left(400^{\circ} \mathrm{C}\right)$, an active replacement process $\left(\mathrm{O}^{16}\right.$ to $\mathrm{O}^{18}$ ) has been found to occur. According to our results, the diffusion characteristics of the oxygen subsystem of $\mathrm{LnMnO}_{3+\delta}$ oxides are similar.

So mechanical activation leads to significant changes in the structural properties of $\mathrm{LnMnO}_{3+\delta}$ oxides and in combination with heat treatment provides equally effective ways to influence the properties, as use nonisovalent substitutions and non-stoichiometry.

\section{Acknowledgements}

This work was carried out under the Programme of Presidium of the Russian Academy of Sciences (12-П-3-1021) and supported by Russian Foundation for Basic Research (grant № 13-03-00597-a).

\section{REFERENCES}

[1] E.L. Nagaev "Colossal-magnetoresistance materials: manganites and conventional ferromagnetic semiconductors" Physics Reports. Vol. 346, Issue 6, 2001, pp. 387-534.

[2] E. Dagotto, T. Hotta, A. Moreo "Colossal magnetoresistant materials: the key role of phase separation" Physics Reports, Vol. 344, Issue 1-3, 2001, pp.1-153
[3] Rezlescu N., Rezlescu E., Doroftei C., Popa P.D., Ignat M. "Nanostructured lanthanum manganite perovskites in catalyst applications". Digest Journal of Nanomaterials \& Biostructures (DJNB), Vol. 8 Issue 2, 2013, p581-587.

[4] P. Shuk, R. Jantz, H.-U. Guth "Oxygen sensor with advanced oxide electrode materials". International Journal on Smart Sensing and Intelligent Systems, Vol. 5, N1, 2012, p.233-245.

[5] Drury O.B., Yong G.J., Kolagani, Rajeswari M., Liang Yong, Gardner C.S., Ables E., Fong K.W., Bionta Richard M., Friedrich S. "Fabrication of Cryogenic Manganite Bolometers to Measure the Total Energy at the LCLS Free Electron X-Ray Laser". Browse Journals \& Magazines, Nuclear Science, IEEE Transactions, V.56, Issue 3, 2009, pp.1114-1120.

[6] A. Pimenov, A.A. Mukhin, V.Yu. Ivanov, V.D. Travkin, A.M. Balbashov, A. Loid "Possible evidence for electromagnons in multiferroic manganites". Condensed Matter, arXiv:cond-mat/0602173, 2006, 4 pages.

[7] M. Fiebig, Th. Lottermoser, D. Frohlich, A.V.Goltsev, R.V. Pisarev "Observation of Coupled Magnetic and Electric Domains". Nature, Vol. 419, 2002, p. 818-820.

[8] N.A. Hill, K.M. Rabe "First principles investigation of ferromagnetism and ferroelectricity in $\mathrm{BiMnO}_{3}$ " Phys. Rev. B 59,1999, p. 8759-8769.

[9] I.A. Abdel-Latif "Rare Earth Manganites and their Applications". Journal of Physics, Vol.1, N3, 2012, pp.15-31.

[10] C. Ritter, M.R. Ibarra, J.M. De Teresa, P.A. Algarabel, C.Marquina, J.Blasco, J. García, S. Oseroff, S-W. Cheong "Influence of oxygen content on the structural, magnetotransport, and magnetic properties of $\mathrm{LaMnO}_{3+\delta}$ ". Phys. Rev., Vol.56, N14, 1997, pp.8902-8911.

[11] Troyanchuk I.O., Khomchenko V.A., Tovar M., Szymczak H., Bärner K. "Antiferromagnet-ferromagnet and structural phase transitions in $\mathrm{La}_{0.88} \mathrm{MnO}_{\mathrm{x}}$ manganites". Phys. Rev. B, Vol. 69, N 5, 2004, pp. 544321-5443212.

[12] A. Urushibara, Y. Moritomo, T. Arima, A. Asamitsu, G. Kido, and Y. Tokura, "Insulator-metal transition and giant magnetoresistance in $\mathrm{La}_{1-\mathrm{x}} \mathrm{Sr}_{\mathrm{x}} \mathrm{MnO}_{3}$ ”. Phys. Rev. B, Vol. 51, 1995, pp.14103-14109.

[13] Dabrowski B., Kolesnik S., Baszczuk A., Chmaissem O., Maxwell T., Mais J. "Structural, transport, and magnetic properties of $\mathrm{RMnO}_{3}$ perovskites $(\mathrm{R}=\mathrm{La}, \mathrm{Pr}, \mathrm{Nd}, \mathrm{Sm}, 153 \mathrm{Eu}$, Dy)" Journal of Solid State Chemistry, Vol.178, 2005, p.629-637.

[14] S.Sankarrajanb, K. Sakthipandi, V. Rajendran "Effect of Rare Earth Ions on Transition Temperature in Perovskite Materials by On-Line Ultrasonic Studies". Materials Research, Vol. 15, N4, 2012, pp. 517-521.

[15] W.J. Kuen, L.K. Pah, A.H. Shaari, C.S. Kien, N. Siau, W. and A. Gan Han Mingl "Effect of Rare Earth Elements Substitution in La site for $\mathrm{LaMnO}_{3}$ Manganites". Pertanika J. Sci. \& Technol., Vol. 20, №1, 2012, pp. 81-88.

[16] J. Seo, B.T. Phan, J. Stahn, J. Lee, C. Panagopoulos "Relaxor characteristics at the interfaces of $\mathrm{NdMnO}_{3} / \mathrm{SrMnO}_{3} / \mathrm{LaMnO}_{3}$ superlattices". Phys. Rev. B, Vol. 82, Issue 14, 2010, pp. 140405 .

[17] F. Hong, Z. Cheng, J. Wang, X. Wang, S. Douet "Positive and 
negative exchange bias effects in the simple perovskite manganite $\mathrm{NdMnO}_{3}$ ". Appl. Phys. Lett., Vol.101, 2012, p. 102411.

[18] E.G. Avvakumov "Mechanical Methods of Activating Chemical Processes" [in Russian], Nauka, Novosibirsk (1986);

[19] V.V.Boldyrev "Mechanochemistry and mechanical activation of solids". Russian Chemical Reviews, Vol.75, N 3, 2006, pp. 177-189.

[20] V.V. Zyryanov "Mechanochemical synthesis of complex oxides". Russian Chemical Reviews, Vol. 77, N 2, 2008, pp. 105-136.

[21] V.B. Vykhodets, et al. "Oxygen diffusion in $\alpha$-Ti. II. The calculation of the concentration profile of impurities in the nuclear microanalysis". The Phys. Metal \& Metallogr., Vol. 64, 1987, pp. 920-923.

[22] B.A. Gizhevskii, A.Ya. Fishman, E.A. Kozlov et al. "Oxygen Isotope Exchange between Gaseous Phase Enriched with ${ }^{18} \mathrm{O}$ Isotope and Nanocrystal Oxides $\mathrm{LaMnO}_{3+\delta}$ Obtained by Severe Plastic Deformation", Defect and Diffusion Forum, Volumes 273-276, 2008, pp. 233-238.

[23] M. Ramstedt, A.V. Shchukarev, S. Sjöberg. "Characterization of hydrous manganite (g-MnOOH) surfaces - an XPS study",
Surface and Interface Analysis, Vol. 34, 2002, pp. 632-636.

[24] A. Ya. Fishman,. M.A. Ivanov, T.E. Kurennykh et al. "Diffusion in concentrated Jahn-Teller systems", Advances in Quantum Chemistry, Vol. 44, 2003, pp. 497- 509.

[25] Ya. Fishman, T.E. Kurennykh, S.A. Petrova et al. "Oxygen isotope exchange in nanocrystal oxides", Journal of NanoResearch, Vol. 7, 2009, pp. 33-41.

[26] Fedorova O.M., Fishman A.Ya., Kurennykh T.E. et al. "Isotope Exchange between ${ }^{18} \mathrm{O}_{2}$ Gas and Mechanoactivated $\mathrm{NdMnO}_{3+\delta}$ Oxide", Defect and Diffusion Forum, Vol. 333, 2013, pp. 193-198.

[27] Fishman A.Ya. et al. "Isotopic Exchange of Gaseous Oxygen with Mechanoactivated Manganese Oxides", Defect and Diffusion Forum, Vol.326-328, 2012, pp. 713-718.

[28] Adda Y., Philbert L. "La diffusion dans les solides", Presses Univ. de France, Paris, 1966.

[29] N.V. Kasper, I.O. Troyanchuk " Study of Jahn-Teller phase transitions in nonstoichiometric $\mathrm{RMnO}_{3+\mathrm{x}}$ orthomanganites (R = La, Nd, Sm, Eu”. J.Phys.Chem.Solids, Vol.57, N11, 1996, pp.1601-1607. 